\title{
MUITAS VEZES É MAIS CÔMODO CONVIVER COM UMA FALSA VERDADE DO QUE MODIFICAR A REALIDADE
}

SCHWARCZ, Lilia Moritz. Sobre o autoritarismo brasileiro. São Paulo: Companhia das Letras, 2019.

Filipe Soares $^{1}$

É preciso coragem de verdade para enfrentar as histórias associadas às construções mitológicas, sobretudo aquelas calcadas no senso comum. A importância de uma resenha do livro de Lilia Schwarcz, "Sobre o autoritarismo brasileiro", não reside exclusivamente na qualidade de seu conteúdo, mas sobretudo na atualidade de seu tema. A vontade da autora em dar uma rápida resposta à crise política a qual atravessamos reveste o livro de importância, uma forma de indicar as raízes históricas do autoritarismo que hoje paira sobre parte da consciência nacional e seu chefe de governo. Se boa parte da sociedade brasileira está estupefata com a expressão pública do conservadorismo, era urgente que um(a) historiador(a) propusesse algumas respostas para dar conta de explicar o recrudescimento do autoritarismo e a violência institucional que ele

\footnotetext{
${ }^{1}$ Doutor em História Social da Amazônia pelo PPHIST-UFPA e mestre em História pela Universidade Federal de Pernambuco. Atua principalmente nos temas de teoria e metodologia da História, Ditadura Militar e História do Brasil República, discursos, políticas governamentais, conflitos agrários, Nordeste e Amazônia. Lecionou no Ensino Superior nas áreas de História Moderna e Contemporânea. Email para contato: menezes.fs@gmail.com. Endereço para o Currículo Lattes: http://lattes.cnpq.br/8658954585705355.
} 
implica. Temos sempre de ter em vista que a história não deve ser direcionada para usufruto exclusivo de seu métier especializado, mas que momentos políticos conturbados exigem que reflexões deste tipo se tornem públicas, ou seja, mais acessíveis. Este é um importante valor do livro em questão.

Chave explicativa para entendermos a abrangência de público a que se destina a obra é a reflexão através da qual a autora encaminha uma diferenciação entre história e memória. Nesse caso, a história seria um procedimento inconcluso, plural, composto por diversos debates, “incompreensões e lacunas”. Já a memória, um procedimento individual de atualização do passado no presente, uma produção. Através da memória se recupera o "presente do passado", fazendo com que o passado também vire presente. Nesse sentido, o que pretende a autora é lembrar, ou seja, repensar o autoritarismo presente encontrando-o no passado. Esta é uma forma de denunciar a nossa História de maneira a não a esquecer, lembrando o que ocorreu no passado para prová-lo no nosso presente. Com isso, podemos entrever que a autora busca produzir memória, uma dada memória do autoritarismo brasileiro que pode ser relembrada, enquanto atitude individual, por todos aqueles que entram em contato com a obra. Assim, a leitura do livro não exigiria um conhecimento prévio da História, mas apenas a capacidade de lembrar, ampliando a abrangência de público do texto e sua capacidade de levar o leitor à crítica do autoritarismo.

Segundo nos conta sua introdução, um dos objetivos da obra é justamente tentar acalmar os ânimos daqueles que não encontram respostas 
para o crescimento acelerado da violência e da intolerância, questões que acompanham o Brasil da atualidade. Para tanto, a autora convida o leitor a uma viagem pela História do Brasil, entendendo as bases de nossa desigualdade e conflito, o terreno fértil aos arranjos autoritários que acompanham a nossa política. Por completude, entende-se que esses regimes forjam sua legitimidade na construção narrativa da harmonia e paz social, mas funcionam de maneira a conservar suas práticas centralizadoras e segregacionistas.

É consenso que a ascensão de Jair Bolsonaro à presidência é um momento inaugural na sexta república, rompendo o quadro democrático proposto na Constituição de 1988. Para tanto, diz Schwarcz que essa ruptura foi orientada através de batalhas retóricas em torno de novas narrativas históricas, construindo uma verdadeira disputa entre regimes autênticos e falsos, causa e consequência da divisão política do Brasil atual.

Nessa batalha retórica, um dos discursos encontrados na tradição autoritária brasileira é a constante reafirmação de um mito nacional, no qual se lê o Brasil como um território onde os problemas nacionais são encarados de maneira harmoniosa e positiva. Essa posição se estabelece numa leitura continuada da história do Brasil. Segundo a autora, o ponto original dessa elaboração é o naturalista Von Martius, um dos fundadores do Instituto Histórico e Geográfico Brasileiro, segundo ela o primeiro responsável por estabelecer a "metáfora das três raças", mito que cria um Brasil harmônico, detentor de uma paz social simbolizada na união das diferentes raças que abriga. No geral, nossos modelos autoritários 
encontram sucesso no uso discursivo dos mitos da nação indivisível escamoteando suas ações segregacionistas. Na concepção da autora, a batalha retórica se materializa na prática governamental da seguinte maneira: o Estado, grande articulador da convivência social, busca sua própria versão da História, promovendo determinados acontecimentos político-militares e "suavizando" problemas que têm raízes históricas e que estão fincados no presente. Essa "história única", postulada pela retórica governamental de caráter autoritário, busca sobretudo naturalizar "estruturas de mando e obediência", sem poupar esforços para exercer seu controle e violência institucional, abandonando, de certo modo, a leitura harmoniosa que embala a sua construção mítica, mas dela se utilizando para evitar o conflito social e a possibilidade de revolta ou contestação da ordem vigente.

Em sua viagem pela história do Brasil, na tentativa de estabelecer as bases onde se assentam a tradição autoritária brasileira, a autora começa pelo tópico "Escravidão e Racismo". A escravidão seria uma instituição colonial aprofundada no Império e persistente na República, sendo também “o racismo filho da liberdade", pois perdura na organização social da contemporaneidade brasileira, uma vez que a população negra não contou com política de integração após 1888 , sendo a discriminação racial algo que perdura na história nacional. Outro ponto importante no trato do capítulo é a discussão que aponta para o vínculo dos projetos autoritários com a prática que remete ao legado colonial, onde se tenta 
sistematicamente "recriar e obscurecer" o papel e a história das populações não europeias.

Dando sequência às temáticas, a autora propõe a investigação do "Mandonismo", uma estrutura herdada da tradição colonial "assenhoriada" e aprofundada na sua forma coronelista. As bases do mandonismo remetem à nossa aristocracia colonial, meritória e não hereditária, onde o reconhecimento do privilégio era individual e tido como um favor do Estado. Nesse sentido, recorre a uma importante questão tratada por Sérgio Buarque de Holanda em "Raízes do Brasil", qual seja, o uso de diminutivos e apelidos pelos subordinados (escravos e colonos) para se direcionar a seu senhor (oligarquia rural). Esse trato consolidou uma linguagem de aproximação entre dominantes e dominados que confundia o público e o privado, ou melhor, uma prática que, ao aproximar as hierarquias distintas, confundia a dominação.

O terceiro tópico é o "Patrimonialismo" e este é mais uma vez apresentado segundo sua base colonialista. Desde o início da ocupação, parte dos colonos centralizava uma série de funções administrativas e de autoridade pública - marca administrativa da colônia brasileira. Nesse meio, cabe uma crítica à maneira com que a autora discute o conceito de patrimonialismo. Ela afirma que a prática atravessa diversos grupos ou estratos sociais e que está ligada ao sentido geral da propriedade. Porém, cabe discutir se no uso do conceito não seria melhor trabalhá-lo a partir da perspectiva que entende o Estado como instrumento de uma classe, no qual o uso e acesso ao patrimônio público seria exclusividade de uma restrita 
camada social abastada. Ou seja, se no período colonial a escravidão funciona como uma verdadeira instituição, aqueles a quem seria possível obter propriedades, acumulá-las, seriam justamente a oligarquia rural, segmento que mantém o domínio político do país por bastante tempo, atravessando o Império e dominando a base de nossa República. Hoje, não podemos esquecer a atualidade que tem o problema da concentração de terras e os privilégios do agronegócio brasileiro quando nos momentos que avançam políticas autoritárias.

Ao desembocar no tópico da "Corrupção", me permitam uma pergunta com a qual indaguei a autora durante a leitura de seu livro. A corrupção é cultural ou estrutural? Nas suas análises Lilia Schwarcz aposta na tese da continuidade histórica e afirma ser a corrupção uma herança dos tempos coloniais, a meu ver, portanto, estrutural. Num esforço de origem, ela retoma um relato fundante de nossa história, a carta de Pero Vaz de Caminha, onde o escrivão chega a apelar ao então rei português que facilite a vida de seu genro. Contudo, ao final, é apresentada a ideia, como encerramento da reflexão, de que a corrupção, nas palavras da autora, constitui um problema endêmico do Brasil, parte do caráter brasileiro e, portanto, fincada na cultura nacional. Importante perceber que o relato fundante das práticas de gestão do Brasil é criado em meio a aspirações corruptivas, o que me faz entender o problema como algo estrutural. Contudo, essa estrutura não é abstrata, mas invadiu a consciência nacional a tal ponto que naturalizou a corrupção nos mais banais atos do dia a dia, aproximando o caráter do brasileiro à estrutura corruptiva de sua 
dominação política. Romper com a corrupção no Brasil é reconfigurar sua estrutura de posse de uma nova cultura, esta última bem distante do mito que consagra o famoso "jeitinho brasileiro".

A “Desigualdade”, por sua vez, é conclamada a partir da escravidão. Nesse tópico, o passado colonial é sempre posto como ponto originário do desequilíbrio social, através justamente da concentração de terras e renda e suas respectivas práticas culturais patrimonialistas. No entanto, entre continuidades e rupturas, a autora infere que aquele tempo não deu conta de esclarecer porque o processo de industrialização do século $\mathrm{XX}$ não foi capaz de romper esse ciclo vicioso do passado, dando uma certa independência histórica ao fenômeno de nossa modernidade e contradizendo a perspectiva de que ela é na verdade carente, fruto de nossa dependência colonial.

Já encaminhando o desfecho do livro, Lilia Schwarcz propõe a discussão da violência, sob sua forma autoritária e institucional. Parte fundamental é a discussão de que, no momento presente, sendo a violência uma marca de nossa história, estaríamos diante de um perigo iminente, tendo em vista os incentivos governamentais à brutalidade, à redução da maioridade penal e ao armamento. Contudo, a autora denuncia que essas medidas não são capazes de reduzir a violência, mas de agravá-la enquanto um grande problema nacional. A violência nas áreas rurais, outra marca de nossa história, é pouco ou quase nada trabalhada pela autora, tratando exclusivamente da questão indígena. Schwarcz aponta que a partir do Império se criou a imagem de que os indígenas a serem valorizados seriam 
aqueles capturados pela cultura nacional única e indivisível. Aqueles sujeitos originários que tendem a valorizar e a defender sua existência, sem passarem pelo processo de aculturação, seriam, enfim, tidos como bárbaros, segmentos a serem excluídos do quadro geral da população justamente por manifestarem sua diferença.

Em "Raça e Gênero", sem muito me alongar no debate, apesar de considerar uma discussão importante para o equilíbrio social na contemporaneidade, apresento o apelo da autora para a criação de políticas públicas afirmativas, uma constante do livro. Mais caro ao esforço intelectual para o entendimento do autoritarismo é a constatação de que o país se constitui na base de desigualdades socioeconômicas que estão atreladas à questão de raça e de gênero, também de geração e de região. Desgastado, mas ainda importante, é o ponto em que Schwarcz comenta que existe um racismo dissimulado no país, reservando à polícia o posto de principal performer da discriminação. A partir desse ponto, ela começa a citar casos de corpos negros vulneráveis como exemplos da violência policial, dentre os quais se destacam o recente assassinato de Marielle Franco e dos quais não podemos deixar de citar a recente chacina em Jacarezinho, no Rio de Janeiro. Outro ponto que remete à questão de raça e de gênero é a cultura do estupro. Ela é, ou ao menos deveria ser, um dos grandes problemas a serem enfrentados pelos governos em suas diversas esferas. Para exemplificar a construção patriarcal que ao longo do tempo tem autorizado, naturalizado e legitimado o estupro, a autora recorre às imagens da colonização, empresa de caráter masculino, onde o território 
colonial americano foi insistentemente representado como um corpo feminino a ser dominado e explorado. Ao final, em "Intolerância", parte fundamental da imposição em torno das políticas afirmativas das minorias reside na perspectiva de que o Brasil é "um país de passado violento, cujo lema nunca foi a 'inclusão' dos diferentes povos, mas sobretudo a sua 'submissão', mesmo que ao preço do apagamento de várias culturas" (SCHWARCZ, 2019: não p.).

Considero relevante encerrar as investigações sobre o autoritarismo a partir do tema da intolerância. De maneira geral, a não aceitação do diferente tem colocado a sociedade brasileira diante de uma perigosa polarização, esta última sempre acompanhada da possibilidade de um recrudescimento da violência por parte dos segmentos que se redescobrem em práticas fascistas. Como apontado no início do texto, a violência institucional é acompanhada por uma cultura política que sustenta o apagamento das diferenças através da defesa de um Brasil que é único e indivisível, nação harmoniosa, onde não há espaço para a reivindicação de determinados grupos historicamente oprimidos. De todo modo, também não podemos esconder que ao longo dos últimos trinta anos nossa frágil democracia tem falhado na constituição de um projeto que não siga a tutelar os privilégios de uma fina camada social branca e abastada. Por fim, a principal contribuição da obra em questão é percebermos que as raízes do nosso recente autoritarismo estão fincadas na nossa memória desde a colônia. Portanto, as práticas políticas conservadoras não constituem um ponto fora da curva de nossa história, mas sobretudo uma constante que 
Cadernos de Clio, Curitiba, v. 12, $\mathrm{n}^{\circ} .1,2021$

remete ao nosso passado mais remoto. Para rompê-las, portanto, faz-se necessário justamente a consciência da nossa continuidade histórica, tensionando o nosso passado no sentido de buscar formas de ruptura no presente, projetando, enfim, um futuro menos dado ao autoritarismo.

\section{Referências}

SCHWARCZ, Lilia Moritz. Sobre o autoritarismo brasileiro. São Paulo: Companhia das Letras, 2019.

Recebido em: 22/02/2021 Aceito em: 18/06/2021 